\title{
PERANCANGAN ULANG KURVA LENGKUNG KAPASITAS WADUK TAPIN DI KABUPATEN TAPIN PROVINSI KALIMANTAN SELATAN
}

\author{
Alvin Najmi ${ }^{{ }^{*}}$, Noordiah Helda ${ }^{2}$ \\ 1) Universitas Lambung Mangkurat Banjar Baru (email : 1610811210006@mhs.ulm.ac.id) \\ 2) Universitas Lambung Mangkurat Banjar Baru (email : noordiah.helda@ulm.ac.id)
}

\section{$\underline{\text { Info Artikel }}$ \\ Riwayat Artikel:}

Dikirim: 26-04-2021

Direvisi :15-06-2021

Diterbitkan:28-06-2021

\section{Keywords :}

Kapasitas Tampungan Kesetimbangan Air Neraca Air

\begin{abstract}
$\underline{\text { ABSTRAK }}$
Waduk Tapin merupakan tampungan air yang ada karena proses pembendungan aliran Sungai Tapin. Waduk Tapin direncanakan memiliki kapasitas tampungan yang besar. Besarnya kapasitas tampungan waduk akan mempengaruhi seberapa besar air yang bisa dimanfaatkan nantinya untuk kebutuhan. Pentingnya mengetahui kapasitas tampungan waduk adalah untuk membuat waduk bekerja dengan optimal agar tidak terjadi masalah bila nantinya digunakan. Metode yang digunakan pada penelitian ini adalah dengan menganalisa ketersediaan air dengan metode F.J Mock, menganalisa kehilangan air akibat outlet dan evaporasi, analisis bathimetri untuk mendapatkan kurva lengkung kapasitas waduk, dan analisis neraca air untuk mengetahui kesetimbangan airnya. Hasil penelitian untuk lengkung kapasitas waduk, didapatkan kapasitas optimal waduk ditunjukkan oleh titik perpotongan antara volume genangan dan luas genangan waduk pada elevasi $+146,2 \mathrm{~m}^{2}$, berdasarkan perhitungan didapat volume waduk $\pm 53.842 .244,566 \mathrm{~m}^{3}$ dan luas genangan $\pm 3.134 .081,768 \mathrm{~m}^{2}$ dan untuk neraca air terlihat ketersediaan air tertinggi terdapat pada bulan Mei yang bernilai $15,607 \mathrm{~m}^{3} / \mathrm{detik}$ dan yang terendah terdapat pada bulan November dengan nilai $5,637 \mathrm{~m}^{3} /$ detik. Kehilangan air tertinggi terdapat pada bulan November dengan nilai $4,450 \mathrm{~m}^{3} /$ detik, yang mana apabila dilihat ketersediaan air di waduk Tapin maka waduk Tapin mampu memenuhi kebutuhan air yang diperlukan.
\end{abstract}

\section{PENDAHULUAN}

\subsection{Latar Belakang}

Kabupaten Tapin merupakan salah satu kabupaten yang ada di Kalimantan Selatan yang sedang giat melakukan pembangunan daerah. Salah satu pembangunan yang sedang dilakukan adalah pembangunan bendungan Tapin yang terletak di Desa Pipitak Jaya, Kecamatan Piani, Kabupaten Tapin. Bendungan Tapin akan dibangun di daerah aliran sungai Tapin yang nantinya akan digunakan untuk mengatasi kerawanan air dan sebagai faktor pendukung pembangunan wilayah kabupaten Tapin.

Waduk Tapin merupakan tampungan air yang ada karena proses pembendungan aliran sungai Tapin sehingga alirannya dapat terbendung untuk menampung volume air dalam jumlah besar agar bisa dimanfaatkan untuk berbagai keperluan. Waduk ini berfungsi sebagai tempat penyimpanan air berlebih saat terjadinya musim penghujan, sebagai kebutuhan air baku, pengairan irigasi untuk pertanian dan pembangkit listrik tenaga air. Untuk pemenuhan kebutuhan tersebut, Waduk Tapin direncanakan memiliki kapasitas tampungan yang besar. Besarnya kapasitas tampungan waduk akan mempengaruhi seberapa besar air yang bisa dimanfaatkan nantinya untuk kebutuhan. Pentingnya mengetahui kapasitas tampungan waduk adalah untuk membuat waduk bekerja dengan optimal agar tidak terjadi masalah bila nantinya digunakan. Tingkat keandalan tampungan debit air dapat menurun sampai dengan 25\% (Limantara et al., 2016). 
Untuk mengetahui besaran tampungan air di waduk Tapin, maka diperlukan adanya lengkung kapasitas tampungan yang dalam penelitian ini akan dilakukan perancangan ulang dengan menggunakan data hidrologi dan klimatologi dari tahun 2011-2019 yang mana akan dianalisis menggunakan metode Penman-Monteith dan F. J. Mock untuk mendapatkan kapasitas optimal tampungan waduk Tapin beserta kesetimbangan airnya untuk penggunaan di berbagai rencana manfaat.

\subsection{Perumusan Masalah}

Adapun perumusan masalah adalah sebagai berikut:

1. Bagaimana pengolahan data bathimetri untuk mendapatkan lengkung kapasitas tampungan waduk Tapin?

2. Bagaimana kesetimbangan air di waduk Tapin apabila digunakan untuk berbagai rencana manfaat?

\subsection{Tujuan Penelitian}

Tujuan dari penelitian yang akan dicapai adalah sebagai berikut:

1 Menganalisis pengolahan data bathimetri untuk mendapatkan lengkung kapasitas tampungan waduk Tapin.

2 Menganalisis kesetimbangan air di waduk Tapin apabila digunakan untuk berbagai rencana manfaat.

\section{METODE PENELITIAN 2.1. Lokasi Penelitian}

Lokasi penelitian ini terletak di Desa Pipitak Jaya, Kecamatan Piani, Kabupaten Tapin, Provinsi Kalimantan Selatan. Bendungan Tapin terletak di Sungai Tapin yang memiliki luas DAS $382 \mathrm{~km}^{2}$, sedangkan luas DAS dengan titik kontrol pada lokasi site Waduk Tapin adalah $140,915 \mathrm{~km}^{2}$ dengan panjang sungai utama $37,48 \mathrm{~km}$. Lokasi bendungan terletak di daerah perbukitan dengan elevasi +90 m sampai +540 $m$ dari dasar sungai sampai rencana bendungan.

\subsection{Pengumpulan Data}

Data yang diperlukan dalam penelitian ini meliputi data primer dan data sekunder. Pengumpulan data primer dilakukan dengan melakukan pengukuran langsung ke lokasi penelitian yaitu Waduk Tapin, Kabupaten Tapin. Pengumpulan data sekunder dilakukan dengan mengunjungi instansi-instansi terkait yang mempunyai data-data terkait obyek penelitian. Data sekunder yang diperoleh meliputi:

1. Data hidrologi yaitu data curah hujan selama 9 tahun terakhir dari tahun 20112019 dari pos hujan Bungur, Kabupaten Tapin.

2. Data klimatologi selama 9 tahun terakhir dari tahun 2011-2019 dari Badan Pusat Statistik Kabupaten Tapin.

\subsection{Analisis dan Pengolahan Data}

Analisis dan pengolahan data dalam penelitian ini meliputi: evapotranspirasi, analisis debit andalan, analisis kehilangan air (akibat outlet, evaporasi, air irigasi, pembangkit listrik, air baku).

\section{Kapasitas Tampungan Waduk}

Kapasitas tampungan waduk dapat dihitung dengan rumus-rumus untuk menghitung volume benda padat. Kapasitas waduk pada kedudukan alamiah biasanya haruslah di tetapkan berdasarkan pengukuran topografi. Perhitungannya berdasarkan peta topografi dengan skala $1: 10.000$ dengan beda tinggi kontur $5 \mathrm{~m}$ atau $10 \mathrm{~m}$ untuk mengetahui luas permukaan genangan bendung yang dibatasi garis kontur, serta mengetahui volume yang dibatasi oleh dua garis kontur yang berurutan dengan menggunakan persamaan pendekatan volume (Soedibyo, 2003).

Lengkung kapasitas waduk merupakan grafik yang menghubungkan luas daerah genangan dengan volume tampungan terhadap elevasinya. Lengkung kapasitas dapat dibentuk dengan cara mengukur luas antara garis kontur di dalam kedudukan waduk. Kumulatif dari lengkung luas dan elevasi tersebut merupakan lengkung kapasitas waduk. Pertambahan tampungan antara dua elevasi dihitung dengan mengalikan luas rata-rata pada elevasi tersebut dengan perbedaan kedua elevasinya. Akumulasi seluruh pertambahan dibawah suatu elevasi tertentu merupakan volume tampungan waduk pada elevasi tersebut. 


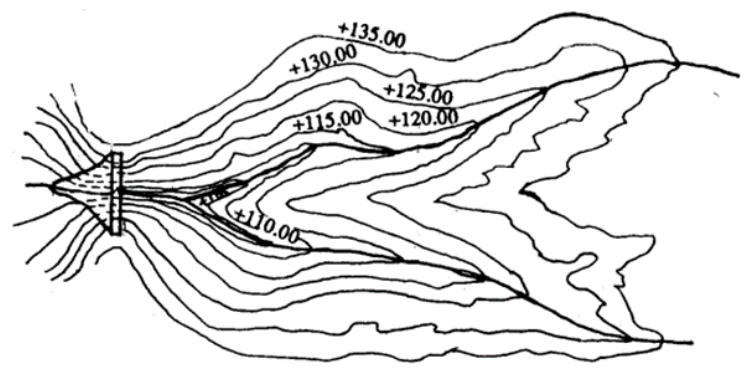

Gambar 1. Lay out dari waduk

Volume antara kontur dapat dicari dengan:

$$
V x=\frac{1}{3} x Z x(F y+F x+\sqrt{F y+F x})
$$

Dimana:

$$
\begin{array}{ll}
\mathrm{Vx} & =\text { Volume pada kontur }\left(\mathrm{m}^{3}\right) \\
\mathrm{Z} & =\text { Beda tinggi antar kontur }(\mathrm{m}) \\
\mathrm{Fy} & =\text { Luas pada kontur } \mathrm{Y}\left(\mathrm{m}^{2}\right) \\
\mathrm{Fx} & =\text { Luas pada kontur } \mathrm{X}\left(\mathrm{m}^{2}\right)
\end{array}
$$

\section{Evapotranspirasi}

Evapotranspirasi adalah perpaduan dua proses yakni evaporasi dan transpirasi yang diartikan sebagai peristiwa kehilangan air dari jaringan tanaman dan permukaan tanah yang dipakai sebagai tempat tumbuhnya tanaman (Hadisusanto, 2011). Untuk menghitung nilai evapotranspirasi potensial (Eto) dengan metode Penmann-Monteith dapat dilihat dari persamaan 2 (SNI 7745:2012) sebagai berikut:

$$
\text { Eto }=\frac{0,408 \Delta R n+\gamma \frac{900}{(T+273)} U_{2}\left(e_{s}-e_{a}\right)}{\Delta+\gamma\left(1+0,34 U_{2}\right)}
$$

\section{Dimana:}

Eto = Evapotranspirasi tanaman acuan (mm/hari)

$\mathrm{Rn} \quad=$ Radiasi matahari netto di atas permukaan tanaman, $\left(\mathrm{MJ} / \mathrm{m}^{2} /\right.$ hari $)$

$\mathrm{T}=$ Suhu udara rata-rata $\left({ }^{\circ} \mathrm{C}\right)$

$\mathrm{U}_{2} \quad=$ Kecepatan angin pada ketinggian $2 \mathrm{~m}$

dari atas permukaan tanah, $(\mathrm{m} / \mathrm{s})$

es $\quad=$ Tekanan uap air jenuh $(\mathrm{kPa})$

ea $\quad=$ Tekanan uap air aktual $(\mathrm{kPa})$

$\Delta \quad=$ Kemiringan kurva tekanan uap air terhadap suhu, $\left(\mathrm{kPa} /{ }^{\circ} \mathrm{C}\right)$

$\gamma \quad=$ Konstanta psikrometrik $\left(\mathrm{kPa} /{ }^{\circ} \mathrm{C}\right)$

\section{Analisa Ketersediaan Air}

Metode Mock (Agus, 2015) digunakan untuk menghitung debit andalan (inflow) sungai dengan konsep keseimbangan air. Hasil perhitungan debit andalan dengan metode Mock dipengaruhi oleh jumlah hujan yang turun di Daerah Aliran Sungai (DAS) yang menjadi limpasan (Run off) dan luas DAS. Nilai limpasan merupakan jumlah dari limpasan langsung (direct Run off) ditambah dengan aliran dasar (baseflow). Adapun rumus yang digunakan dalam perhitungan metode Mock sebagai berikut:

$$
Q n=\frac{R O \times 10^{-3} \times A}{d}
$$

Dimana:

$$
\begin{array}{ll}
\text { Qn } & =\text { Debit andalan }\left(\mathrm{m}^{3} / \text { detik }\right) \\
\text { RO } & =\text { Baseflow }+ \text { Direct run off }(\mathrm{mm} / \text { bulan }) \\
\text { A } & =\text { Luas DAS }\left(\mathrm{m}^{2}\right) \\
\text { d } & =\text { Jumlah hari dalam satu bulan }
\end{array}
$$

\section{Analisa Kehilangan Air}

Kehilangan air atau jumlah air yang keluar (Outflow) adalah kehilangan air akibat berbagai macam faktor seperti debit keluar melalui outlet, air yang menguap akibat evaporasi, kehilangan air akibat pengolahan air baku, ataupun pengolahan listrik dengan tenaga air. Sofandi (2019) menyatakan bahwa Kehilangan air dapat disebabkan oleh evaporasi saluran, rembesan pada saluran, serta eksploitasi saluran irigasi. Kehilangan akibat evaporasi pada seluruh saluran terjadi sebanyak 0,386 lt/dt. Kehilangan air akibat eksploitasi terjadi sebanyak 4,167 $1 \mathrm{t} / \mathrm{dt}$. Beberapa faktor yang mempengaruhi kehilangan air sebagai berikut.

\section{Kehilangan Air Akibat Outlet}

Kehilangan air pada outlet ialah jumlah air yang keluar dari outlet menuju saluran primer yang digunakan untuk memenuhi kebutuhan air di hilir waduk Tapin misalnya untuk irigasi. Kehilangan tinggi tekanan di bagian ini sama seperti kehilangan tekanan pada tabung pendek, debit aliran (Q) yang masuk ke dalam mulut pengambilan adalah:

$$
Q=C A(2 g h)^{1 / 2}
$$

Dimana:

C = Koefisien aliran, 


$$
\begin{array}{ll}
\mathrm{A} & =\text { Luas bukaan, }(\mathrm{m}) \\
\mathrm{h} & =\text { Tinggi tekanan }(\text { head }), \\
\mathrm{g} & =\text { Gravitasi, }
\end{array}
$$

\section{Kehilangan Air Akibat Evaporasi}

Kehilangan air akibat evaporasi yang terjadi di waduk Tapin dapat dihitung dengan berbagai rumus Herbeck, Balaguru (2019) menyebutkan metode yang sering digunakan untuk mengetahui kehilangan air akibat evaporasi pada waduk yang besar adalah rumus Herbeck. Untuk itu pada penelitian ini akan digunakan rumus Herbeck dalam perhitungannya. Berikut ini merupakan rumus Herbeck (1962):

$$
E=N U_{2}(e s-e a)
$$

Dengan:

$$
N=\frac{0,0291}{A_{S}^{0.05}}
$$

Dimana:

$$
\begin{array}{ll}
\mathrm{E} & =\text { Evaporasi } \\
\mathrm{U}_{2} & =\text { Kecepatan angin } 2 \mathrm{~m} \text { diatas permukaan } \\
\text { es } & =\text { Tekanan uap jenuh } \\
\text { ea } & =\text { Tekanan uap aktual }
\end{array}
$$

\section{Kehilangan Air Akibat Air Irigasi}

Dalam mengalirkan air irigasi dari sumber (sungai, waduk) sampai ke lahan pertanian akan mengalami kehilangan-kehilangan air sehingga berkurangnya debit air yang dibutuhkan. (Iswinarti, 2016). Priyonugroho (2014) menyebutkan bahwa kebutuhan air irigasi menurut metode perhitungan manual maksimal adalah $2,54 \mathrm{~m}^{3} / \mathrm{dt}$ dan minimalnya adalah 0,17 $\mathrm{m}^{3} / \mathrm{dt}$. Sedangkan metode CROPWAT maksimalnya adalah $1,67 \mathrm{~m}^{3} / \mathrm{dt}$ dan minimalnya adalah 0,06 $\mathrm{m}^{3} / \mathrm{dt}$. Adapun perhitungan air irigasi berdasarkan luasan lahan digunakan rumusan sebagai berikut:

Dimana:

$$
Q=H \times\left(\frac{A}{T}\right) \times 10.000
$$

$\mathrm{Q}=$ Kebutuhan air irigasi $\left(\mathrm{m}^{3} / \mathrm{dt} / \mathrm{ha}\right)$

$\mathrm{H}=$ Tinggi genangan air $(\mathrm{mm})$

$\mathrm{A}=$ Luas daerah irigasi (ha)

$\mathrm{T}=\mathrm{Waktu}$ pemberian air (hari/detik)

Kehilangan Air Akibat Pembangkit Listrik

Pembangkit listrik tenaga air adalah pembangkit energi yang terbarukan (renewable) yang memanfaatkan energi potensial dan kinetik dari air untuk menghasilkan energi listrik. Penelitian
Suharthama (2015) menunjukkan bahwa beban minimum $10 \%$ membutuhkan daya mekanik 405,9 $\mathrm{kW}$ dengan debit air 1,25 $\mathrm{m}^{3} / \mathrm{s}$ dan beban maksimum $100 \%$ membutuhkan daya mekanik $3.410,4 \mathrm{~kW}$ dengan debit air 10,55 $\mathrm{m}^{3} / \mathrm{s}$. Berdasarkan aliran rencana debit air PLTM Tukad Balian mampu dibebani hingga 80\% dengan daya mekanik 2699,7 $\mathrm{kW}$ dan debit air $8,35 \mathrm{~m}^{3} / \mathrm{s}$.

Adapun rumus untuk perhitungan Daya Teoritis $(\mathrm{Pt})$ menggunakan rumus berikut:

$$
P t=g \times Q \times H
$$

Dimana:

$$
\begin{array}{ll}
\mathrm{Pt} & =\text { Daya teoritis }(\mathrm{kWh}) \\
\mathrm{g} & =\text { Gaya gravitasi }\left(\mathrm{m} / \mathrm{s}^{2}\right) \\
\mathrm{Q} & =\text { Debit andalan }\left(\mathrm{m}^{3} / \mathrm{s}\right) \\
\mathrm{H} & =\text { Tinggi terjunan }(\mathrm{m})
\end{array}
$$

\section{Kehilangan Air Akibat Air Baku}

Seiring dengan bertambahnya jumlah penduduk, kebutuhan akan air baku akan semakin meningkat. Kebutuhan air baku dalam hal ini adalah air yang digunakan untuk kebutuhan rumah tangga (domestik). Untuk itu diperlukan adanya perhitungan untuk mengetahui seberapa besar kebutuhan air baku. Adapun rumus untuk menghitung kebutuhan air baku sebagai berikut:

$$
Q r h=P \times q
$$

Dimana:

$$
\begin{array}{ll}
\text { Qrh } & =\text { Kebutuhan air baku }\left(\mathrm{m}^{3} / \text { detik }\right) \\
\mathrm{g} & =\text { Jumlah penduduk } \\
\mathrm{Q} & =\text { Standar kebutuhan domestik }
\end{array}
$$

\section{Neraca Air}

Neraca air (water balance) merupakan neraca masukan dan keluaran air di suatu tempat pada periode tertentu, sehingga dapat diketahui jumlah air tersebut kelebihan (surplus) ataupun kekurangan (defisit). Hadryana et al., (2015) melakukan penelitian tentang ketersediaan debit air Sungai Sungi dan kebutuhan debit air Sungai Sungi untuk memenuhi kebutuhan air baku dan irigasi.. Pada perencanaan hidrologi, perhitungan neraca air dapat membantu menerangkan aliran air yang masuk dan keluar pada suatu sistem. Pada perhitungan neraca air, terdapat parameterparameter yang sulit diukur di lapangan terutama yang berhubungan dengan parameter 
pada air tanah, tetapi dalam perumusannya sering dilakukan penyederhanaan sesuai dengan kondisi lapangan setempat. Perhitungan neraca air sering dilakukan untuk tujuan:

1. Menghitung persediaan air pada permukaan tanah dan sub-permukaan tanah.

2. Menaksir pola penggunaan air yang tersedia.

3. Membantu untuk menseimbangkan jumlah air yang lebih dari kekurangan air.

4. Sebagai dasar pada perhitungan perencanaan optimasi pada manajemen sumber daya air.

Adapun rumus untuk menghitung neraca air adalah:

$$
\Delta S=\text { Inflow }- \text { Outflow }
$$

Dimana:

Inflow = Ketersediaan air

Outflow = Kehilangan air

\section{HASIL DAN PEMBAHASAN}

\subsection{Evapotranspirasi}

Sebelum melakukan perhitungan debit andalan menggunakan metode F. J. Mock, terlebih dahulu melakukan perhitungan evapotranspirasi, evapotranspirasi merupakan gabungan antara evaporasi dan transpirasi yang merupakan proses terjadinya kehilangan air dari tanaman dan permukaan tanah. Untuk mendapatkan nilai evapotranspirasi ada berbagai metode, salah satunya metode Penman-Monteith. Adapun data klimatologi yang dibutuhkan untuk perhitungan ini yaitu:

1. Data temperatur $(\mathrm{t})$

2. Data kelembaban udara $(\mathrm{Rh})$,

3. Data penyinaran matahari $(\mathrm{n} / \mathrm{N})$, dan

4. Data kecepatan angin (U).

Adapun rumus yang digunakan dalam perhitungan evapotranspirasi menggunakan metode Penman-Monteith adalah sebagai berikut:

$$
\text { Eto }=\frac{0,408 \Delta R n+\gamma \frac{900}{(T+273)} U_{2}\left(e_{s}-e_{a}\right)}{\Delta+\gamma\left(1+0,34 U_{2}\right)}
$$

Hasil perhitungan evapotranspirasi bulanan dengan menggunakan metode Penman-Monteith dapat dilihat pada Gambar 1 berikut ini:

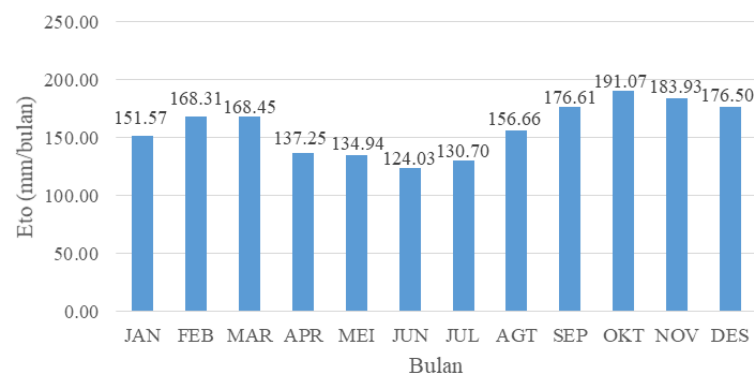

Gambar 1. Grafik Evapotranspirasi (Eto) ratarata

Berdasarkan Gambar 1 dapat dilihat nilai evapotranspirasi rata-rata maksimum terdapat pada bulan oktober dengan nilai 191,07 $\mathrm{mm} /$ bulan, sedangkan nilai Eto rata-rata minimum terdapat pada bulan juni dengan nilai $124,03 \mathrm{~mm} / \mathrm{bulan}$. Selanjutnya nilai evapotranspirasi rata-rata ini akan digunakan untuk melakukan perhitungan ketersediaan air dengan menghitung debit andalan menggunakan metode F.J. Mock.

\subsection{Analisis Debit Andalan}

Metode F. J. Mock digunakan untuk menghitung debit andalan (inflow) dengan konsep keseimbangan air. Ada beberapa faktor yang mempengaruhi besaran nilai debit andalan mulai dari data jumlah curah hujan, jumlah hari hujan, nilai evapotranspirasi potensial, daerah tangkapan hujan dan hari dalam satu bulan. Adapun rumus yang digunakan dalam perhitungan debit andalan dengan metode $F$. $J$. Mock adalah sebagai berikut:

$$
Q n=\frac{\text { Run Off } \times \text { Luas DAS }}{n}
$$

Pada perhitungan ini akan menggunakan jumlah curah hujan pada pos hujan Bungur pada tahun 2011 sampai dengan tahun 2019, Hasil perhitungan debit andalan rata-rata menggunakan metode $F$. J. Mock dapat dilihat pada Gambar 2 sebagai berikut: 


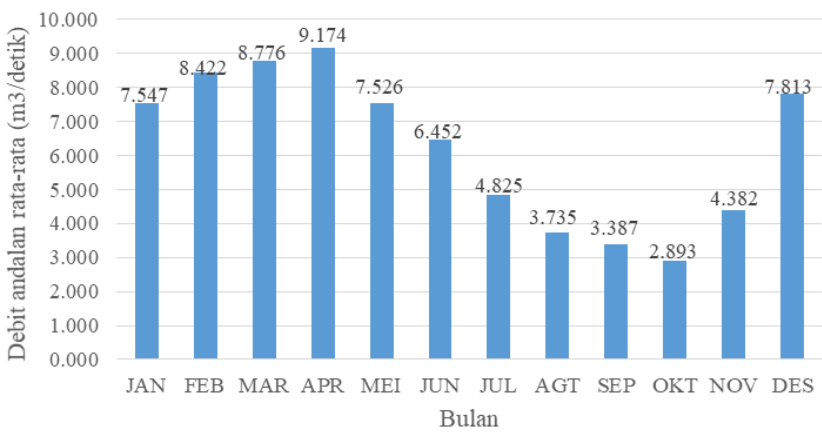

Gambar 2. Grafik Debit Andalan rata-rata

Gambar 2 menunjukkan debit andalan rata-rata maksimum pada bulan april dengan nilai debit andalan sebesar 9,174 $\mathrm{m}^{3} /$ detik sedangkan untuk debit andalan rata-rata minimum pada bulan oktober sebesar $2.893 \mathrm{~m}^{3} /$ detik. Untuk pengaliran irigasi diperlukan debit andalan mencapai $80 \%-90 \%$ melalui perhitungan debit andalan (Abdulsalam et al., 2014; Irpan et al., 2013; Mashuri et al., 2015; Sudinda, 2019). Salah satu cara dalam menghitung debit andalan adalah dengan cara Plotting Position Weibul. Adapun rumusnya:

$$
R=\frac{r}{N+1}
$$

Debit andalan yang digunakan dalam penelitian ini adalah sebesar $80 \%$. Berdasarkan Gambar 3 dapat dilihat debit andalan $80 \%$ terbesar terdapat pada bulan april dengan nilai sebesar 7,712 $\mathrm{m}^{3} /$ detik sedangkan untuk debit andalan $80 \%$ terendah terdapat pada bulan november dengan nilai sebesar $1.615 \mathrm{~m}^{3} /$ detik. Hasil perhitungan debit andalan $80 \%$ menggunakan metode Plotting Position Weibul dapat dilihat pada Gambar 3 berikut:

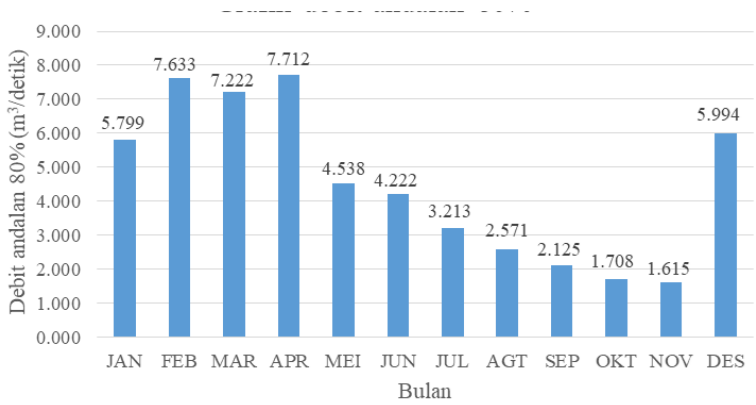

Gambar 3. Grafik Debit Andalan $80 \%$

\subsection{Analisis Kehilangan Air}

Kehilangan air atau jumlah air yang keluar (outflow) dari waduk Tapin dapat disebabkan oleh hal berikut:

\section{Kehilangan Air Akibat Outlet}

Kehilangan air akibat outlet yaitu jumlah air yang keluar dari outlet menuju saluran primer yang digunakan untuk memenuhi kebutuhan air di hilir waduk Tapin misalnya untuk irigasi. Kehilangan tinggi tekanan di bagian ini sama seperti kehilangan tekanan pada tabung pendek, debit aliran $(\mathrm{Q})$ yang masuk ke dalam mulut pengambilan adalah :

$Q=C A(2 g h)^{\frac{1}{2}}$

Contoh perhitungan:

$Q=C A(2 g h)^{1 / 2}$

$Q=0,7 \times(1,8 \times 1,8) \times(2 \times 9,8 \times 0,5618)^{1 / 2}$

$Q=7,530 \mathrm{~m}^{3} / \mathrm{dtk}$

Hasil perhitungan kehilangan air akibat outlet dengan berbagai luas bukaan dapat dilihat pada Tabel 1 berikut:

Tabel 1. Outlet Dengan Berbagai Lebar Bukaan

\begin{tabular}{ccccc}
\hline $\begin{array}{c}\text { Lebar } \\
\text { Bukaan } \\
\mathrm{m}\end{array}$ & $\begin{array}{c}\text { Koefisien } \\
\text { Aliran }\end{array}$ & $\begin{array}{c}\text { Gaya } \\
\text { Gravitasi } \\
\mathrm{m} / \mathrm{d}^{2}\end{array}$ & $\begin{array}{c}\text { Tinggi } \\
\text { Tekanan }\end{array}$ & $\begin{array}{c}\text { Debit } \\
\text { Keluar } \\
\mathrm{m}^{3} / \mathrm{d}\end{array}$ \\
\hline 1,8 & 0,7 & 9,81 & 0,5618 & 7,530 \\
\hline 1,7 & 0,7 & 9,81 & 0,5618 & 7,111 \\
\hline 1,6 & 0,7 & 9,81 & 0,5618 & 6,693 \\
\hline 1,5 & 0,7 & 9,81 & 0,5618 & 6,275 \\
\hline 1,4 & 0,7 & 9,81 & 0,5618 & 5,857 \\
\hline 1,3 & 0,7 & 9,81 & 0,5618 & 5,438 \\
\hline 1,2 & 0,7 & 9,81 & 0,5618 & 5,020 \\
\hline 1,1 & 0,7 & 9,81 & 0,5618 & 4,602 \\
\hline 1,0 & 0,7 & 9,81 & 0,5618 & 4,183 \\
\hline 0,9 & 0,7 & 9,81 & 0,5618 & 3,765 \\
\hline 0,8 & 0,7 & 9,81 & 0,5618 & 3,347 \\
\hline 0,7 & 0,7 & 9,81 & 0,5618 & 2,928 \\
\hline 0,6 & 0,7 & 9,81 & 0,5618 & 2,510 \\
\hline 0,5 & 0,7 & 9,81 & 0,5618 & 2,092 \\
\hline 0,4 & 0,7 & 9,81 & 0,5618 & 1,673 \\
\hline 0,3 & 0,7 & 9,81 & 0,5618 & 1,255 \\
\hline 0,2 & 0,7 & 9,81 & 0,5618 & 0,837 \\
\hline 0,1 & 0,7 & 9,81 & 0,5618 & 0,418 \\
\hline & & & &
\end{tabular}




\section{Kehilangan Air Akibat Evaporasi}

Kehilangan air akibat evaporasi yang terjadi di waduk Tapin dapat dihitung dengan menggunakan rumus Herbeck (1962) berikut ini:

$E=N U_{2}\left(e_{s}-e_{a}\right)$

$N=\frac{0,0291}{A s^{0.05}}$

$$
\begin{aligned}
& N=\frac{0,0291}{\left(141 \times 10^{-6}\right)^{0.05}}=0,011 \\
& E=0,011 \times 0,888(27,645-22,493) \\
& E=0,052 \mathrm{~m}^{3} / \text { detik }
\end{aligned}
$$

Hasil perhitungan kehilangan air akibat evaporasi dapat dilihat pada Tabel 2 berikut:

Tabel 2. Hasil Perhitungan Evaporasi di Waduk Tapin

\begin{tabular}{ccccccc}
\hline Bulan & $\mathrm{U}(\mathrm{km} /)$ & $\mathrm{U}(\mathrm{m} / \mathrm{d})$ & $\mathrm{N}$ & es & ea & $\mathrm{E}\left(\mathrm{m}^{3} / \mathrm{d}\right)$ \\
\hline Januari & 3,196 & 0,888 & 0,011 & 27,645 & 22,493 & 0,052 \\
\hline Februari & 2,702 & 0,751 & 0,011 & 28,502 & 22,256 & 0,053 \\
\hline Maret & 2,423 & 0,673 & 0,011 & 28,502 & 22,154 & 0,049 \\
\hline April & 3,025 & 0,840 & 0,011 & 28,278 & 22,681 & 0,054 \\
\hline Mei & 2,510 & 0,697 & 0,011 & 28,831 & 22,741 & 0,048 \\
\hline Juni & 2,700 & 0,750 & 0,011 & 28,401 & 22,778 & 0,048 \\
\hline Juli & 2,919 & 0,811 & 0,011 & 28,358 & 22,351 & 0,055 \\
\hline Agustus & 5,202 & 1,445 & 0,011 & 28,538 & 21,496 & 0,116 \\
\hline September & 4,121 & 1,145 & 0,011 & 28,986 & 21,312 & 0,100 \\
\hline Oktober & 3,438 & 0,955 & 0,011 & 30,599 & 21,289 & 0,101 \\
\hline November & 3,658 & 1,016 & 0,011 & 29,889 & 19,862 & 0,116 \\
\hline Desember & 3,046 & 0,846 & 0,011 & 27,755 & 23,034 & 0,045 \\
\hline
\end{tabular}

\section{Kehilangan Air Akibat Air Irigasi}

Waduk Tapin direncanakan dapat mengaliri 5.472 hektar daerah irigasi Tapin. Mawardi (2007) menyebutkan ada beberapa fase pemenuhan kebutuhan air yaitu (1) untuk pengelolaan tanah dan persemaian selama 1-1,5 bulan diperlukan ketinggian genangan 10-14 $\mathrm{mm} /$ hari, (2) pertumbuhan pertama yakni selama 1-2 bulan dengan kebutuhan air 4-6 mm/hari, (3) pertumbuhan kedua selama 1-1,5 bulan dengan kebutuhan air 6-8 mm/hari, dan (4) pemasakan selama lebih kurang 1-1,5 bulan dengan kebutuhan air 5-7 mm/hari.

Daerah kabupaten tapin pada umumnya menggunakan padi lokal yang dimana waktu persemaiannya terbagi menjadi 3 yakni pensemaian I (taradakan) dimulai pada bulan oktober selama 35-40 hari, lalu persemaian II (ampakan) dimulai setelah persemaian I yakni bulan november selama 35-45 hari, dan persemaian III (malacak) dimulai setelah persemaian II pada bulan januari selama 50-70 hari sebelum dilakukan penanaman pada bulan maret dan panen pada bulan agustus.

Jadi untuk ketinggian air untuk tanaman padi di kabupaten tapin, Oktober - Februari sebanyak $12 \mathrm{~mm} /$ hari dan Maret - Agustus kebutuhan air $6 \mathrm{~mm} / \mathrm{hari}$ untuk bulan September akan dianggap nol. Contoh perhitungan untuk bulan Oktober:

$Q=H \times(A / T) \times 10.000$

$Q=0,012 \times(5472 /(31 \times 86400)) \times 10.000$

$Q=0,245 \mathrm{~m}^{3} /$ detik

Hasil perhitungan kehilangan air akibat air irigasi dapat dilihat pada Tabel 3 berikut: 
Tabel 3. Hasil Perhitungan Kehilangan Air akibat Irigasi

\begin{tabular}{ccccc}
\hline Bulan & Hari & $\mathrm{H}(\mathrm{m})$ & $\mathrm{A}(\mathrm{ha})$ & $\mathrm{Q}\left(\mathrm{m}^{3} / \mathrm{d}\right)$ \\
\hline Oktober & 31 & 0,012 & 5472 & 0,245 \\
\hline November & 30 & 0,012 & 5472 & 0,253 \\
\hline Desember & 31 & 0,012 & 5472 & 0,245 \\
\hline Januari & 31 & 0,012 & 5472 & 0,245 \\
\hline Februari & 28 & 0,012 & 5472 & 0,271 \\
\hline Maret & 31 & 0,006 & 5472 & 0,123 \\
\hline April & 30 & 0,006 & 5472 & 0,127 \\
\hline Mei & 31 & 0,006 & 5472 & 0,123 \\
\hline Juni & 30 & 0,006 & 5472 & 0,127 \\
\hline Juli & 31 & 0,006 & 5472 & 0,123 \\
\hline Agustus & 31 & 0,006 & 5472 & 0,123 \\
\hline September & 30 & 0 & 5472 & 0 \\
\hline
\end{tabular}

\section{Kehilangan Air Akibat Air Baku}

Diketahui dari data teknis direncanakan waduk Tapin dapat dimanfaatkan untuk keperluan air baku dengan besaran :

$$
Q=0,50 \mathrm{~m}^{3} / \text { detik }
$$

\section{Kehilangan Air Akibat Pembangkit Listrik}

Untuk kebutuhan pembangkit listrik tenaga air sebanyak 1000 MW maka digunakan persamaan 2. Yang mana diketahui dari data Teknis $\mathrm{H}=$ $43,86 \mathrm{~m}$ dan $\mathrm{g}=9,8 \mathrm{~m} / \mathrm{s}$

$$
\begin{gathered}
P=Q \times H \times g \\
Q=\frac{1000}{43,86 \times 9,8}=2,326 \mathrm{~m}^{3} / \text { detik }
\end{gathered}
$$

\subsection{Analisis Data Bathimetri}

Analisis data bathimetri digunakan untuk mengetahui kondisi dasar waduk Tapin, yang mana pengolahan datanya akan menghasilkan kontur yang berguna untuk perhitungan volume waduk Tapin. Prahasta (2002) menggunakan data spasial atau Geographic Information Sistem (GIS) untuk menganalisis data bathimetri. Ada beberapa aplikasi yang digunakan untuk melakukan analisis data bathimetri yaitu Google Earth, Global Mapper, dan AutoCAD Civil 3D. Google Earth digunakan untuk menentukan lokasi yang akan dicari konturnya, Global Mapper digunakan untuk pengolahan data dari Google Earth dan Digital Elevation Model yang hasil pengolahan data dari Global Mapper akan dilihat menggunakan AutoCAD Civil $3 D$ untuk mendapatkan nilainya untuk perhitungan kurva lengkung kapasitas waduk Tapin.

Dari pengolahan data bathimetri didapatkan Lay out kontur waduk Tapin pada Gambar 4 berikut:

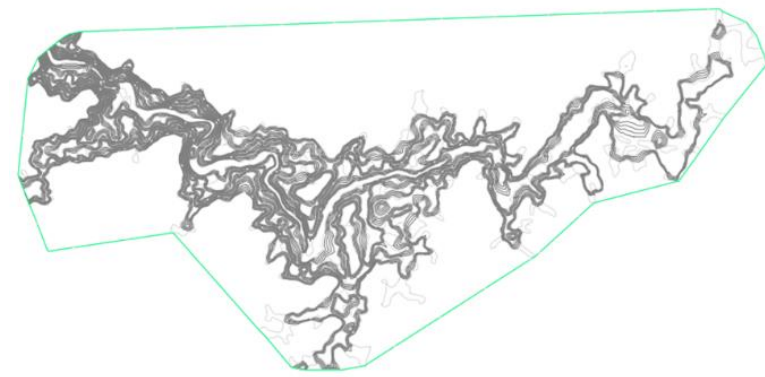

Gambar 4. Lay Out Waduk Tapin

\section{Perhitungan Volume Waduk Tapin}

Perhitungan volume waduk dilakukan dengan data luas dan elevasi. Berikut data-data yang digunakan:
A1 (luas pada elevasi 90m) $\quad=0 \mathrm{~m}^{2}$
A2 (luas pada elevasi $91 \mathrm{~m}$ ) $\quad=20.140,07 \mathrm{~m}^{2}$
$\mathrm{H}$ (beda tinggi antar elevasi) $\quad=1 \mathrm{~m}$

Volume $=\frac{1}{3} \times H \times \sqrt{A 1+A 2(A 1 \times A 2)}$

Maka,

$$
\begin{aligned}
& V=\frac{1}{3} \times 1 \times \sqrt{0+20.140,07(20.140,07 \times 0.0)} \\
& \mathrm{V}=6.713,36 \mathrm{~m}^{3}
\end{aligned}
$$

Adapun Perhitungan selanjutnya dapat dilihat pada Tabel 4 berikut: 
Tabel 4. Hasil Perhitungan Volume Waduk Tapin

\begin{tabular}{|c|c|c|c|c|c|}
\hline Elevasi (m) & $\mathrm{H}(\mathrm{m})$ & Luas $\left(\mathrm{m}^{2}\right)$ & Luas Kumulatif $\left(\mathrm{m}^{2}\right)$ & Volume $\left(\mathrm{m}^{3}\right)$ & Volume Kumulatif (m) \\
\hline 131 & 1 & $156.592,78$ & $1.513 .031,02$ & $1.434 .021,97$ & $19.499 .797,15$ \\
\hline 132 & 1 & $70.499,57$ & $1.583 .530,59$ & $1.548 .147,03$ & $21.047 .944,18$ \\
\hline 133 & 1 & $70.961,28$ & $1.654 .491,87$ & $1.618 .881,62$ & $22.666 .825,80$ \\
\hline 134 & 1 & $71.645,68$ & $1.726 .137,55$ & $1.690 .188,16$ & $24.357 .013,96$ \\
\hline 135 & 1 & $72.330,08$ & $1.798 .467,63$ & $1.762 .178,88$ & $26.119 .192,85$ \\
\hline 136 & 1 & $73.014,35$ & $1.871 .481,98$ & $1.834 .853,74$ & $27.954 .046,59$ \\
\hline 137 & 1 & $73.583,86$ & $1.945 .065,84$ & $1.908 .155,67$ & $29.862 .202,26$ \\
\hline 138 & 1 & $74.781,66$ & $2.019 .847,50$ & $1.982 .339,12$ & $31.844 .541,38$ \\
\hline 139 & 1 & $83.105,33$ & $2.102 .952,83$ & $2.061 .260,55$ & $33.905 .801,93$ \\
\hline 140 & 1 & $189.999,31$ & $2.292 .952,14$ & $2.197 .267,82$ & $36.103 .069,75$ \\
\hline 141 & 1 & $355.942,99$ & $2.648 .895,13$ & $2.468 .784,42$ & $38.571 .854,17$ \\
\hline 142 & 1 & $110.662,95$ & $2.759 .558,08$ & $2.704 .037,89$ & 41.275.892,07 \\
\hline 143 & 1 & $108.605,06$ & $2.868 .163,14$ & $2.813 .685,94$ & $44.089 .578,00$ \\
\hline 144 & 1 & $109.789,24$ & 2.977.952,38 & $2.922 .885,93$ & $47.012 .463,93$ \\
\hline 145 & 1 & $111.020,87$ & $3.088 .973,25$ & $3.033 .293,50$ & $50.045 .757,43$ \\
\hline 146 & 1 & $112.274,68$ & $3.201 .247,93$ & $3.144 .943,58$ & $53.190 .701,01$ \\
\hline 147 & 1 & $113.267,91$ & $3.314 .515,84$ & $3.257 .717,79$ & $56.448 .418,79$ \\
\hline 148 & 1 & $113.788,48$ & $3.428 .304,32$ & $3.371 .250,05$ & $59.819 .668,84$ \\
\hline 149 & 1 & $120.015,69$ & $3.548 .320,01$ & $3.488 .140,10$ & $63.307 .808,95$ \\
\hline 150 & 1 & $453.482,07$ & $4.001 .802,08$ & $3.772 .789,21$ & $67.080 .598,16$ \\
\hline 151 & 1 & $337.814,01$ & 4.339.616,09 & 4.169.568,54 & $71.250 .166,70$ \\
\hline 152 & 1 & $124.262,93$ & $4.463 .879,02$ & $4.401 .601,38$ & $75.651 .768,08$ \\
\hline 153 & 1 & $123.538,60$ & 4.587.417,62 & $4.525 .507,80$ & $80.177 .275,88$ \\
\hline 154 & 1 & $123.803,01$ & $4.711 .220,63$ & 4.649.181,76 & $84.826 .457,64$ \\
\hline 155 & 1 & $123.924,04$ & $4.835 .144,67$ & $4.773 .048,59$ & $89.599 .506,22$ \\
\hline 156 & 1 & $124.044,52$ & 4.959.189,19 & 4.897.036,01 & $94.496 .542,23$ \\
\hline 157 & 1 & $124.222,74$ & $5.083 .411,93$ & $5.021 .172,51$ & $99.517 .714,74$ \\
\hline 158 & 1 & $126.375,17$ & $5.209 .787,10$ & $5.146 .470,21$ & $104.664 .184,95$ \\
\hline 159 & 1 & $147.055,83$ & $5.356 .842,93$ & $5.283 .144,46$ & $109.947 .329,41$ \\
\hline
\end{tabular}

Membuat Grafik Lengkung Kapasitas Waduk

Dari perhitungan volume, kemudian dibuat grafik hubungan antara elevasi volume waduk dari grafik tersebut dapat di cari luas dari volume bendung setiap elevasi tertentu dari waduk. Adapun Grafik Lengkung Kapasitas Waduk dapat dilihat pada Gambar 5 berikut: 


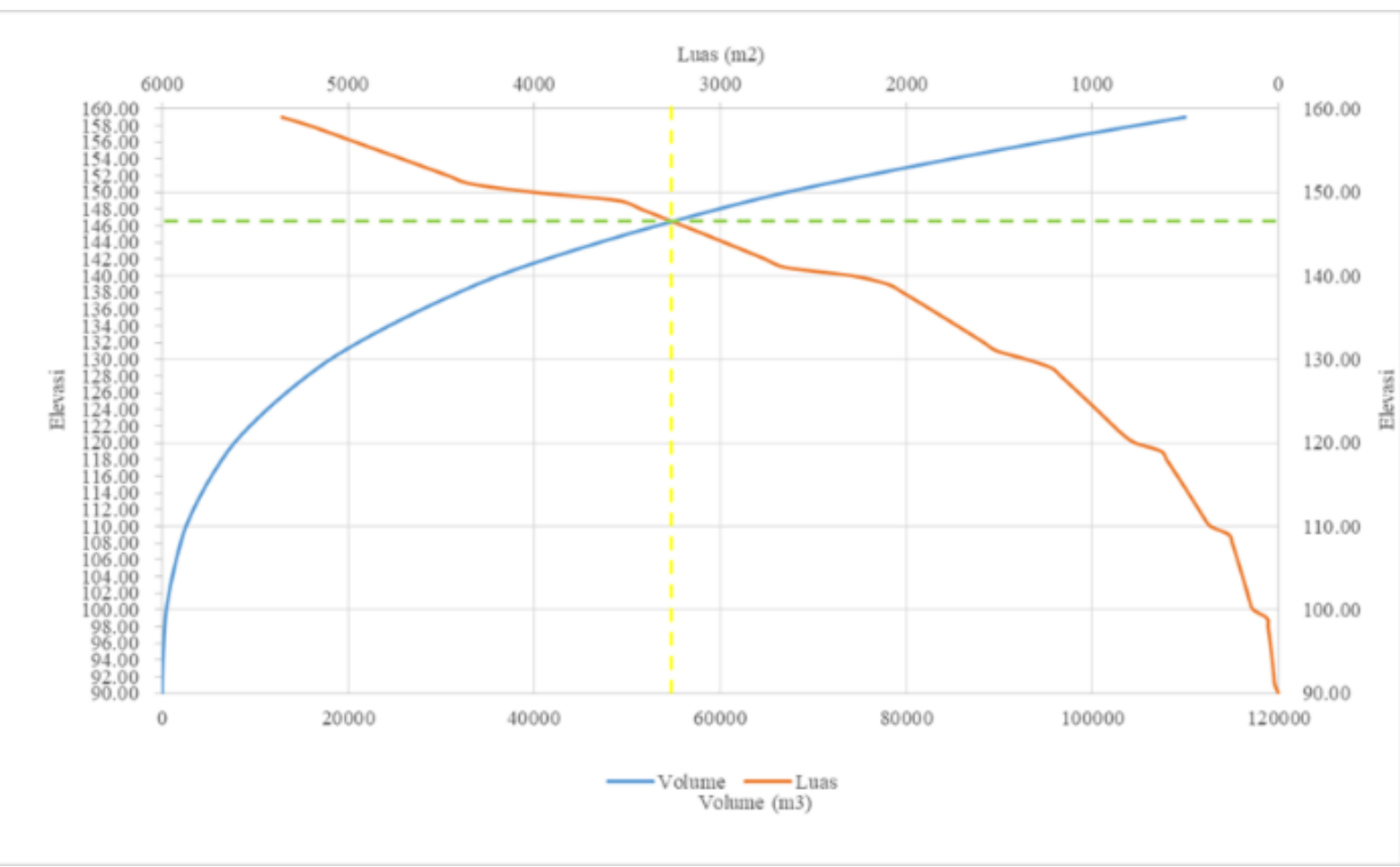

Gambar 5. Grafik Lengkung Kapasitas Waduk

Berdasarkan Gambar 5. grafik lengkung kapasitas waduk, kapasitas optimal waduk ditunjukkan oleh titik perpotongan antara volume genangan dan luas genangan waduk pada elevasi +146,2 mdpl, berdasarkan perhitungan luas dan volume yang ada pada tabel volume kapasitas tampungan waduk pada elevasi $+146,2$ adalah $\pm 53.842 .244,566 \mathrm{~m}^{3}$ dengan luas genangan $\pm 3.134 .081,768 \mathrm{~m}^{2}$.

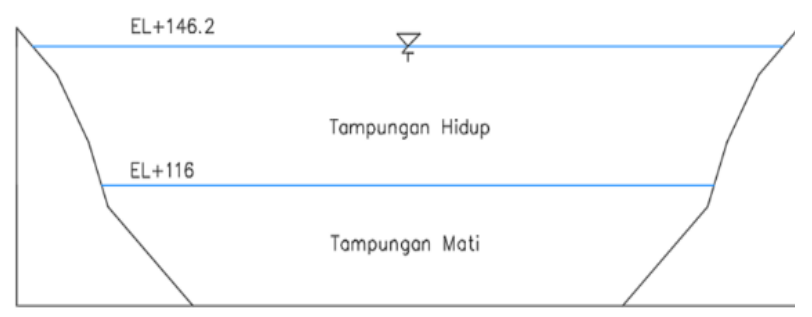

Gambar 6. Tampungan Waduk Tapin
Pada Gambar 6 diatas dapat dilihat tampungan waduk Tapin yang dimana pada elevasi $+146,2$ $m$ merupakan elevasi optimal waduk dan pada +116 m berdasarkan data teknis merupakan elevasi outlet waduk.

\subsection{Analisa Neraca Air}

Kondisi neraca air di waduk Tapin dihitung dengan persamaan kontinuitas berikut ini:

$$
\text { Inflow }- \text { Outflow }= \pm \Delta S
$$

Inflow yang digunakan diambil dari debit andalan $80 \%$ sedangkan untuk outflow diambil dari outlet dengan bukaan $0,3 \mathrm{~m}$, evaporasi, untuk air irigasi karena tidak dihitung pola tanam maka keluaran air dianggap sama setiap bulan, air baku dan pembangkit listrik tenaga air. Hasil perhitungan neraca air di waduk Tapin dapat dilihat pada Tabel 5 berikut ini:

Tabel 5. Perhitungan Neraca Air

\begin{tabular}{|c|c|c|c|c|c|c|c|c|c|c|c|}
\hline \multirow{2}{*}{ Bulan } & \multicolumn{3}{|c|}{ Ketersediaan Air (Inflow) } & \multicolumn{6}{|c|}{ Kehilangan Air (Outflow) } & \multirow{2}{*}{$\frac{\text { Neraca Air }}{\Delta \mathbf{S}}$} & \multirow{2}{*}{ Keterangan } \\
\hline & Debit $80 \%$ & Sisa Air & Total & Outlet & Evaporasi & Irigasi & Air Baku & PLTA & Total & & \\
\hline JAN & 5,799 & 0,000 & 5,799 & 1,255 & 0,052 & 0,245 & 0,500 & 2,326 & 4,378 & 1,421 & Memenuhi \\
\hline FEB & 7,633 & 1,421 & 9,053 & 1,255 & 0,053 & 0,271 & 0,500 & 2,326 & 4,406 & 4,648 & Memenuhi \\
\hline MAR & 7,222 & 4,648 & 11,870 & 1,255 & 0,049 & 0,123 & 0,500 & 2,326 & 4,252 & 7,618 & Memenuhi \\
\hline APR & 7,712 & 7,618 & 15,330 & 1,255 & 0,054 & 0,127 & 0,500 & 2,326 & 4,261 & 11,069 & Memenuhi \\
\hline MEI & 4,538 & 11,069 & 15,607 & 1,255 & 0,048 & 0,123 & 0,500 & 2,326 & 4,252 & 11,355 & Memenuhi \\
\hline
\end{tabular}




\begin{tabular}{|c|c|c|c|c|c|c|c|c|c|c|c|}
\hline \multirow{2}{*}{ Bulan } & \multicolumn{3}{|c|}{ Ketersediaan Air (Inflow) } & \multicolumn{6}{|c|}{ Kehilangan Air (Outflow) } & \multirow{2}{*}{$\frac{\text { Neraca Air }}{\Delta \mathbf{S}}$} & \multirow{2}{*}{ Keterangan } \\
\hline & Debit $80 \%$ & Sisa Air & Total & Outlet & Evaporasi & Irigasi & Air Baku & PLTA & Total & & \\
\hline JUN & 4,222 & 11,355 & 15,577 & 1,255 & 0,048 & 0,127 & 0,500 & 2,326 & 4,256 & 11,322 & Memenuhi \\
\hline JUL & 3,213 & 11,322 & 14,535 & 1,255 & 0,055 & 0,123 & 0,500 & 2,326 & 4,259 & 10,276 & Memenuhi \\
\hline $\mathrm{AGU}$ & 2,571 & 10,276 & 12,847 & 1,255 & 0,116 & 0,123 & 0,500 & 2,326 & 4,319 & 8,528 & Memenuhi \\
\hline SEP & 2,125 & 8,528 & 10,653 & 1,255 & 0,100 & 0,000 & 0,500 & 2,326 & 4,181 & 6,472 & Memenuhi \\
\hline OKT & 1,708 & 6,472 & 8,180 & 1,255 & 0,101 & 0,245 & 0,500 & 2,326 & 4,427 & 3,752 & Memenuhi \\
\hline $\mathrm{NOV}$ & 1,615 & 3,752 & 5,367 & 1,255 & 0,116 & 0,253 & 0,500 & 2,326 & 4,450 & 0,917 & Memenuhi \\
\hline DES & 5,994 & 0,917 & 6,911 & 1,255 & 0,045 & 0,245 & 0,500 & 2,326 & 4,372 & 2,539 & Memenuhi \\
\hline
\end{tabular}

Berdasarkan Tabel 5 kemudian dibuat menjadi grafik neraca air seperti pada Gambar 7 berikut:

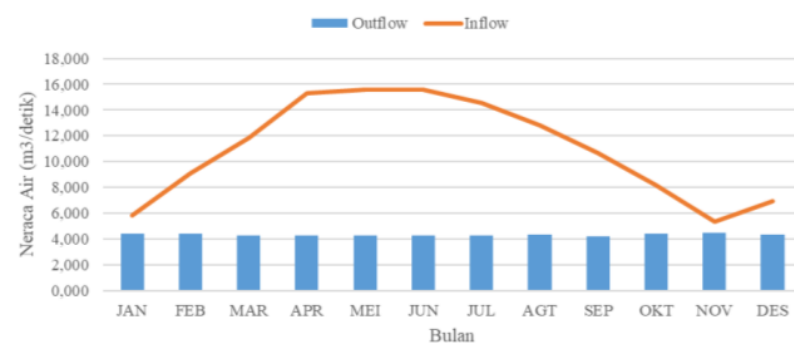

Gambar 7. Grafik Neraca Air di Waduk Tapin

Dari Gambar 7 terlihat ketersediaan air tertinggi terdapat pada bulan Mei yang bernilai $15,607 \mathrm{~m}^{3} /$ detik dan yang terendah terdapat pada bulan November dengan nilai $5,637 \mathrm{~m}^{3} /$ detik. Kehilangan air tertinggi terdapat pada bulan November dengan nilai $4,450 \mathrm{~m}^{3} /$ detik. Artinya jika dilihat ketersediaan airnya maka waduk Tapin mampu memenuhi kebutuhan air yang diperlukan.

\section{KESIMPULAN}

Dari perancangan ulang kurva lengkung kapasitas waduk Tapin diperoleh beberapa kesimpulan sebagai berikut:

1. Lengkung kapasitas waduk Tapin menunjukkan volume tampungan berada pada elevasi $+146,2$ adalah $\pm 53.842 .244,566 \mathrm{~m}^{3}$ dengan luas genangan $\pm 3.134 .081,768 \mathrm{~m}^{3}$.

2. Dari hasil neraca air terlihat ketersediaan air tertinggi terdapat pada bulan Mei yang bernilai $15,607 \mathrm{~m}^{3} /$ detik dan terendah terdapat pada bulan November dengan nilai $5,637 \mathrm{~m}^{3} /$ detik. Kehilangan air tertinggi terdapat pada bulan November dengan nilai $4,450 \mathrm{~m}^{3} /$ detik, yang mana apabila dilihat ketersediaan air maka waduk Tapin mampu memenuhi kebutuhan air yang diperlukan.

\section{UCAPAN TERIMA KASIH}

Ucapan terima kasih disampaikan kepada seluruh pihak-pihak yang telah membantu kelancaran dalam pelaksanaan penelitian ini.

\section{DAFTAR PUSTAKA}

Abdulsalam, R., Binilang, A., \& Halim, F. (2014). Analisis Potensi Sungai Atep Oki serta Desain Dasar Bangunan Sipil Untuk Pembangkit Listrik Tenaga Air. Jurnal Sipil Statik Universitas Sam Ratulangi, 2(5), pp. 225-232 https://ejournal.unsrat. ac.id/ index.php/jss/article/view/5765

Agus, A. S. (2015). Analisis Kapasitas Tampungan Waduk Sungai Paku Kecamatan Kampar Kabupaten Kampar. Jurnal Online Mahasiswa (JOM) Fakultas Teknik Universitas Riau, 2(2), pp.1-7 https://jom.unri.ac.id/index.php/JOMFTE KNIK/article/view/8217

Badan Standardisasi Nasional. (2012). SNI 7745:2012 Tata Cara Perhitungan Evapotranspirasi Tanaman Acuan Dengan Metode Penman-Monteith.

Balaguru, M., Sankaran, S., \& Ilavarasan, N. (2019). Estimation of Evaporation Loss in Red hills Lake at Thiruvallur District, Tamil Nadu. International Research Journal of Multidisciplinary Technovation, 1(6), pp. 569-581. https://journals.iorpress.org/index.php/ irjmt/article/view/264

Brown, G. C. (2005). The Texas Manual on Rainwater Harvesting. Austin: Texas Water Development Board.

Hadisusanto, N. (2011). Aplikasi Hidrologi. Malang : Jogja Media Utama. 
Hardryana, I M. A., Arsana, I G. N. K., \&

P, I P. G. S. (2015). Analisis Keseimbangan Air/Water Balance di Das Tukad Sungi Kabupaten Tabanan. Jurnal Ilmiah Teknik Sipil Universitas Udayana, 19(2), pp. 99107. https://ojs.unud.ac.id/index.php/jits/ article/view/24103

Irpan, A., Sujatmoko, B., \& Hendri, A. (2014). Analisa Kapasitas Embung Untuk Suplai Air Irigasi (Studi Kasus: Desa Sendayan, Kecamatan Kampar Utara). Jurnal Online Mahasiswa (JOM) Fakultas Teknik Universitas Riau, 1(1), pp. 1-14. https://jom.unri.ac.id/index.php/ JOMFTEKNIK/article/view/3749

Iswinarti, I. (2016). Kehilangan Air Akibat Rembesan Ke Dalam Tanah, Beserta Perhitungan Effesiensinya Pada Saluran Irigasi Sekunder Rejoagung I dan II. Jurnal Intake: Jurnal Penelitian Ilmu Teknik dan Terapannya, 7(2), pp. 25-35. https://ejournal.ft-undar.ac.id/index.php/ intake/article/view/20

Limantara, L. M., \& Putra, W. R. (2016). Analisa Keandalan Tampungan Waduk di Embung Tambak Pocok Bangkalan. Jurnal Teknik Sipil ITB Bandung, 23(2), pp. 127-134.https://journals.itb.ac.id/ index.php/jts/article/view/2933

Mashuri, M., Fauzi, M., \& Sandhyavitri, A. (2015). Kajian Ketersediaan dan Kebutuhan Air Baku Dengan Permodelan IHACRES di Daerah Aliran Sungai Tapung Kiri. Jurnal Online Mahasiswa (JOM) Fakultas Teknik Universitas Riau, 2(1), pp. 1-12.https://jom.unri.ac.id/index. php/JOMFTEKNIK/article/view/6245

Mawardi, E. (2007). Desain Hidraulik Bangunan Irigasi, Bandung: Alfabeta.

Prahasta, E. (2002). Sistem Informasi Geografis: Konsep-Konsep Dasar Informasi Geografis. Bandung: Informatika Bandung.

Priyonugroho, A. (2014). Analisis Kebutuhan Air Irigasi (Studi Kasus Pada Daerah Irigasi Sungai Air Keban Daerah Kabupaten Empat Lawang). Jurnal Teknik Sipil dan Lingkungan Fakultas Teknik
Universitas Sriwijaya Palembang, 2(3), pp. 457-470.

Pusat Pendidikan dan Pelatihan Sumber Daya Air dan Konstruksi, Badan Pengembangan Sumber Daya Manusia, Kementerian Pekerjaan Umum dan Perumahan Rakyat. (2017). Hidrologi, Ketersediaan, dan Kebutuhan Air: Pelatihan Alokasi Air. Bandung.

Pusat Pendidikan dan Pelatihan Sumber Daya Air dan Konstruksi, Badan Pengembangan Sumber Daya Manusia, Kementerian Pekerjaan Umum dan Perumahan Rakyat. (2017). Pelatihan Perencanaan Bendungan Tingkat Dasar. Bandung.

Pusat Pendidikan dan Pelatihan Sumber Daya Air dan Konstruksi, Badan Pengembangan Sumber Daya Manusia, Kementerian Pekerjaan Umum dan Perumahan Rakyat. (2016). Perencanaan Bendung Utama (Bendung) Diklat Teknis Perencanaan Irigasi Tingkat Dasar. Bandung.

Sudinda, T. W. (2019). Penentuan Debit Andalan Dengan Metoda F. J. Mock di Daerah Aliran Sungai Cisadane. Jurnal Air Indonesia Pusat Teknologi Lingkungan BPPT, 11(1), pp. 15-24. http://ejurnal2.bppt.go.id/index.php/JAI/ar ticle/viewFile/3933/3243

Soedibyo. (2003). Teknik Bendungan. Pradnya Paramita, Jakarta.

Sofandi, H. (2019). Analisis Kehilangan Air Pada Saluran Irigasi Daerah Irigasi Sudi Mampir Kecamatan Rancaekek Kabupaten Bandung. Skripsi. Universitas Komputer Bandung.https://elibrary. unikom.ac.id/id/eprint/1257/

Suharthama, W. G., Wijaya, I W. A., \& Janardana, I G. N. (2015). Analisa Daya Pembangkit Listrik Tenaga Minihidro Tukad Balian, Tabanan Menggunakan Simulink. E-Jurnal Spektrum Fakultas Teknik, Universitas Udayana, 2(2), pp. 110-114.

https://ojs.unud.ac.id/index.php/spektrum/ article/view/20022 